\title{
How Does Openness Affect the Innovation Performance of Private Enterprises?
}

\author{
Jiacheng Xin \\ School of Business \\ Yunnan University of Finance and \\ Economics \\ Kunming, China \\ 1511323969@qq.com
}

\author{
Qicheng Lu* \\ School of Business \\ Yunnan University of Finance and \\ Economics \\ Kunming, China \\ 317404322@qq.com
}

\author{
Lei Pei \\ School of Business \\ Yunnan University of Finance and \\ Economics \\ Kunming, China
}

\begin{abstract}
Open innovation is an important way for private enterprises to improve their innovation performance. However, there is still much controversy about how corporate openness affects corporate innovation performance. The paper uses the micro data of China's private manufacturing enterprises published by the World Bank to demonstrate. Research shows that enterprise open innovation has a significant role in promoting corporate innovation performance. The above findings further reveal the complex mechanism of the openness of private enterprises affecting innovation performance, enrich the research results of the relationship between openness and innovation performance, and have important guiding significance for the open innovation practice of private enterprises in China.
\end{abstract}

Keywords: open innovation, openness, innovation performance

\section{INTRODUCTION}

Open innovation is an important way for private enterprises to improve their innovation performance (Chinese Entrepreneur Survey System, 2017) [1], which provides a good opportunity and way for the development of technological capabilities of private enterprises such as Geely Automobile [2], significantly improving the private sector in China. Enterprise innovation performance [3]. In recent years, China is in the critical period of economic transformation and is shifting from a high-speed growth phase to a high-quality development phase. The 19th National Congress of the Communist Party of China clearly stated: "We must establish a technological innovation system with enterprises as the mainstay, market-oriented, and deep integration of production, education and research, and strengthen innovation support for small and medium-sized enterprises." In this environment of social and economic development, enterprises If internal innovation alone is far from meeting market competition requirements, it is necessary to seek cooperation with external organizations to obtain more innovative resources. This makes many companies take the initiative to adopt an open innovation strategy when they are making product or technology innovations, essentially changing the innovation process of the enterprise, exploring the deeper innovation potential of the enterprise, enhancing the core competitiveness of the enterprise, and thus enhancing the innovation of the enterprise. Performance. In addition, from a general logical point of view, the institutional environment must have an impact on the innovation performance of enterprises. Especially for China, due to its special national conditions, the government is highly inductive to the innovation activities of enterprises, so the differences in institutional environment are likely to have different effects on the performance of open innovation. Even in the same institutional environment, different types of business performance will respond differently. However, how the openness of enterprises affects the innovation performance of enterprises is still an unsolved black box, which greatly hinders the practice of open innovation of private enterprises. Therefore, how to open up private enterprises in this special institutional environment in China is still an unsolved black box, which greatly hinders the development of private enterprises in China.

The relationship between enterprise openness and its innovation performance is a research hotspot in the field of innovation, and has achieved many results, but its conclusion is very controversial, mainly manifested in the following three representative views. First, many studies have found a clear positive correlation between firm openness and its innovation performance. For example, Keupp and Gassmann found through a large amount of data collation and related model tests that the higher the openness of the enterprise, the faster the new product development and the higher the profit margin [4]. Leiponen and Helfat observed that "open thinking" (target breadth) and "information acquisition strategy" (resource depth) have positively contributed to their innovation performance through observations of some representative companies in Finland [5]. The empirical research on domestic enterprise samples also found that the breadth and depth of enterprise innovation and openness have a positive impact on its absorptive capacity and innovation performance [6,7]. Second, some scholars believe that the negative impact of corporate openness on their innovation performance should not be ignored. Sapienza et al pointed out that the increase in openness will make the company's innovation resources and focus more dispersed, which is not conducive to the company's own key technical research, nor can it form its own unique advantages, and even increase its dependence on external technology. In fact, it reduces the independent research and development capabilities of enterprises [8].

*Corresponding author 
Knudsen et al.'s research also shows that most of the technology alliances formed by various enterprises in the innovation process have not undergone rigorous risk assessment, which makes the original advantages and innovation information of the enterprise easy to be competitors. Obtained, resulting in erosion of interests [9]. Huang and Rice also believe that companies that value independent technology development will have better innovation performance and sustainable development capabilities than those that rely on foreign technology for a long time [10]. Wang et al. also found that R\&D Openness has a negative impact on the company's own innovation output through empirical research on 279 Chinese companies [11]. Third, there are some important studies that show that there is not a simple linear relationship between firm openness and its innovative performance. Laursen and Salter's research finds that there is an "inverted U-shaped" relationship between the breadth and depth of open innovation and its innovative performance [12]. At the same time, it is believed that the breadth and depth of open innovation of enterprises have complementary effects on their innovation performance, and this conclusion is also supported by domestic research $[13,14]$. These inconsistent conclusions not only lay a foundation for our research, but also provide useful reference. It also shows that it is urgent to study the complex relationship between enterprise openness and innovation performance from a new perspective.

In view of the above disputes and existing deficiencies, this paper innovatively proposes the use of private enterprises as a research sample, reveals the complex relationship between the openness of private enterprises and the innovation performance of enterprises, and deepens the understanding of the relationship between the two. At the same time, it also provides theoretical guidance for the open innovation practice of private enterprises in China.

\section{RESEARCH DESIGN}

\section{A. Enterprise Open Innovation and Its Innovation Performance}

Private enterprises can expand their openness to obtain external creative and complementary resources to help enterprises shorten the research and development cycle and save R\&D investment costs, thereby accelerating the internalization of internal technology and improving the competitive advantage of enterprises. However, in this process, enterprises need to bear certain risk costs, so openness may have a positive or negative impact on the innovation performance of enterprises. On the one hand, corporate openness will have a positive impact on corporate innovation performance. The external export and exchange of enterprises to strengthen technology and creativity can enhance the market location advantage of enterprises, expand the market scope and increase market competitiveness. Lichtenthaler's research shows that companies gain R\&D support and establish industry standards by selling patent licenses in the process of exportoriented open innovation [15]. This external technology outflow and the establishment of industry standards are conducive to increasing the intangible assets of enterprises, thus helping enterprises to bring new market areas, obtain more resources and form competitive advantages. On the other hand, openness may also have a negative effect on corporate innovation performance. When companies cooperate with competitors, they will face the problem of core technology leakage. Even if they cooperate with non-competitors, they will face the problem that non-competitors will leak core technologies to competitors. Once the core technology is leaked, the company will lose its core competitiveness and thus be at a disadvantage in the competition with competitors in the same field. In addition, attention theory believes that management attention is also an important resource. When managers pay too much attention to external cooperation, it will lead to the dispersion of the company's own attention, thus losing the ability to control the innovation interests of the enterprise. Therefore, whether the openness of the enterprise is in a linear positive correlation with the innovation performance of the enterprise, or whether the nonlinear inverted U-shaped relationship requires further research and discussion. Therefore the paper makes the following assumptions:

Hla: Under the conditions of controlling other influencing factors, the higher the openness of private enterprises in the open innovation process, the higher their innovation performance.

H1b: Under the condition of controlling other influencing factors, the openness of the open innovation process of the enterprise is "inverted $U$ " relationship with its innovation performance.

\section{B. Variable selection and data source}

1) Variable measurement: Innovative performance of enterprises (Innoperf), most of the literature uses the number of patents, the number of new products, research and development expenditures, new product listing rate, etc. as a measure. Taking into account the actual situation of private enterprises in China: the increase in the number of patent applications does not necessarily lead to actual innovation performance [16], the innovation performance of SMEs is not always reflected in patents and applications. Therefore, we refer to the existing literature to select the new product sales rate [17], that is, the proportion of new product or service sales revenue to total revenue as a proxy variable for the company's innovation performance, see Table I .

Enterprise open innovation, this article measures open innovation from the two aspects of open innovation behavior choice (CORD) and openness (OD). (1) Research and Development Cooperation (CORD), which is measured by "whether it has research and development cooperation with other companies" in the questionnaire. (2) Openness (OD), measured by the number of external resources of the "businesses with suppliers, customers, universities or research institutions" in the questionnaire. If the company does not cooperate with all three resources, the openness is 1 ; if one of the three is 2 , two of the three are 3; the above three have 4 .

Selection of control variables: (1) Executive gender, by the number of female executives in the questionnaire. (2) Executive experience, through the questionnaire "the number of years the general manager works in the department". (3) The 
degree of informatization, the value of the number of employees using computers in the questionnaire, see Table 1.

Table I. Name and meaning of the variable

\begin{tabular}{cccc}
\hline $\begin{array}{c}\text { Variable } \\
\text { type }\end{array}$ & $\begin{array}{c}\text { Primary } \\
\text { variable }\end{array}$ & Secondary variable & $\begin{array}{c}\text { Basic } \\
\text { indicator }\end{array}$ \\
\hline $\begin{array}{c}\text { Explained } \\
\text { variable }\end{array}$ & $\begin{array}{c}\text { Innovation } \\
\text { performan } \\
\text { ce }\end{array}$ & $\begin{array}{c}\text { Revenue from sales of new } \\
\text { products or services to total } \\
\text { revenue }\end{array}$ & Innoperf \\
Explanatory & Open & R\&D cooperation & CORD \\
variables & innovation & Openness & OD \\
\hline & & Executive gender & Lnexe_exp \\
Control & $\begin{array}{c}\text { The basic } \\
\text { situation }\end{array}$ & Executive experience & H_female \\
& of & Degree of informatization & Infor_deg \\
\hline
\end{tabular}

2) Data Sources: The data in this paper is from the 2012 World Bank survey of Chinese manufacturing companies*. This data uses a stratified random sampling method to survey a total of 2,700 private enterprises and 148 state-owned enterprises. For the accuracy of the analysis, the following data is excluded from this paper: (1) the sales of new products account for the missing value of total sales; (2) the value of R\&D cooperation and openness is missing; (3) the gender of executives The experience of executives and the degree of informatization are missing values. Finally, 669 effective observations of private enterprises were selected, from 25 cities, covering 18 industries. From the descriptive statistics of the survey data in Table 2 , it can be seen that the average value of innovation performance of enterprises is 0.24 , the variance is 0.52 ; the average value of $R \& D$ cooperation is 0.21 , the variance is 0.4 ; the average value of openness is 2.17 , and the variance is 1.08. Although the above-mentioned values reflect the overall level of innovation performance of Chinese manufacturing enterprises, the degree of difference is relatively high (probably due to the wide variety of enterprises, and the different industries and scales of enterprises have different requirements and capabilities for innovation). However, it will not affect the empirical analysis of the relevant issues in this paper. At the same time, it can be seen from the data in Table II that openness, R\&D cooperation, executive gender, and employee informatization degree are significantly positively correlated with corporate innovation performance, while executive experience is significantly negatively correlated with corporate innovation performance. After testing, R\&D cooperation, openness, executive experience, executive gender, and informational degree variance expansion factors (VIF) were 1.194, 1.203, 1.043, 1.024 , and 1.304, respectively, and there was no significant multicollinearity problem.
TABLE II. DESCRIPTIVE STATISTICS AND COEFFICIENTS OF VARIABLES

\begin{tabular}{lllllllll}
\hline variable & Mean & SD & $\mathbf{1}$ & $\mathbf{2}$ & $\mathbf{3}$ & $\mathbf{4}$ & $\mathbf{5}$ & $\mathbf{7}$ \\
\hline 1.Innoperf & 0.24 & 0.52 & 1 & & & & & \\
2.OD & 2.17 & 1.08 & $0.26^{* *}$ & 1 & & & & \\
3.CORD & 0.21 & 0.40 & $0.31^{* *}$ & $0.41^{* *}$ & 1 & & & \\
4.H_female & 0.09 & 0.28 & $0.76^{*}$ & 0.44 & -0.62 & 1 & & \\
5.Lnexe_exp & 2.75 & 0.20 & $-0.10^{* *}$ & $0.89^{*}$ & $0.14^{* * *}$ & $-0.99^{* *}$ & 1 & \\
6.Infor_deg & 2.81 & 0.54 & $0.84^{*}$ & 0.68 & 0.70 & $0.88^{*}$ & -0.11 & 1 \\
\hline
\end{tabular}

\section{EMPIRICAL ANALYSIS AND DISCUSSION OF RESULTS}

Based on the previous theoretical basis, models (1) and (2) were constructed to test hypotheses $\mathrm{H} 1 \mathrm{a}$ and $\mathrm{H} 1 \mathrm{~b}$ to examine the relationship between open innovation and innovation performance of private enterprises.

$$
\begin{aligned}
& \text { Innoperf }=\mathrm{P}_{6}+\mathrm{B}_{2} C O R D+\mathrm{P}_{2} O D+\mathrm{P}_{2} \sum_{i=1} \text { Control t s } \\
& \text { Innoperf }=\mathrm{P}_{6}+\mathrm{P}_{2} C O R D+\mathrm{P}_{2} O D+\mathrm{P}_{2} O D^{2}+\mathrm{P}_{4} \sum_{i=1} \text { Control } \mathrm{H}_{5}
\end{aligned}
$$

Among them: Innoperf represents enterprise innovation performance; CORD and OD represent enterprise $R \& D$ cooperation and openness respectively; Control represents a list of control variables, including executive gender, executive experience and information level.

The regression results are shown in Table III : the regression coefficient of $R \& D$ cooperation and openness on the innovation performance of enterprises in model (1) is significantly positively correlated at the level of 0.01 , and the square term of openness does not pass the significance test, which shows that The openness of private enterprises in the process of open innovation is significantly positively correlated with their innovation performance, and this relationship is linear, assuming that $\mathrm{H} 1 \mathrm{a}$ is established, and that $\mathrm{H} 1 \mathrm{~b}$ is not established. This is consistent with the analysis results of Keupp and scholars such as Leiponen and Helfat ${ }^{[4][5]}$

\begin{tabular}{|c|c|c|}
\hline Variable & Model(1)coefficient & Model (2) coefficient \\
\hline \multirow[t]{2}{*}{ OD } & $2.117^{* *}$ & $3.538^{*}$ \\
\hline & $(2.429)$ & 1.866 \\
\hline \multirow[t]{2}{*}{ CORD } & $5.203 * *$ & $5.137 * *$ \\
\hline & $(2.317)$ & $(2.278)$ \\
\hline \multirow[t]{2}{*}{$\mathrm{OD}^{2}$} & & -0.296 \\
\hline & & $(-0.356)$ \\
\hline \multirow[t]{2}{*}{ H_female } & 2.993 & $3.00 * *$ \\
\hline & $(2.75)$ & (1.09) \\
\hline \multirow[t]{2}{*}{ Lnexe_exp } & $-4.201 * *$ & $-4.170^{* *}$ \\
\hline & $(1.867)$ & $(-2.229)$ \\
\hline \multirow[t]{2}{*}{ Infor_deg } & 0.85 & 0.847 \\
\hline & $(0.771)$ & $(0.768)$ \\
\hline $\mathrm{F}$ & $5.148 * *$ & 4.304 \\
\hline $\mathrm{R}^{2}$ & 0.145 & 0.136 \\
\hline Adjusted R2 & 0.147 & 0.140 \\
\hline $\begin{array}{l}\text { Number of } \\
\text { samples }\end{array}$ & 669 & 669 \\
\hline
\end{tabular}
but the conclusions of the openness of the enterprise and the 
inverted U-shaped relationship of the enterprise and the inverted U-shaped relationship between the enterprise openness and the innovation performance of enterprises such as Laursen, Chen Yufen and Wei Jie are inconsistent $[12,13,14]$. The reason for this result may be that the open innovation of most private enterprises in China is still in its infancy, and the negative impact of excessive openness on innovation performance is not significant.

\section{CONCLUSION}

This paper uses the World Bank's 2012 China Manufacturing Enterprise Survey data to confirm the impact of open innovation of private enterprises on their innovation performance and the different adjustment roles played by different dimensions of the institutional environment in this process. The empirical results show that enterprise open innovation has a significant impact on its innovation performance, and enterprise open innovation can enhance its innovation performance, and the two are linearly related.

Although the open innovation of Chinese enterprises has gradually become a trend, how to conduct action selection and performance evaluation for different types of enterprises is an urgent problem to be solved in front of us, especially for the majority of private enterprises. Considering that private enterprises have the characteristics of low management level, limited resources and short life cycle compared with stateowned enterprises, this paper puts forward the following suggestions: First, private enterprises can consider adopting an open innovation strategy to improve enterprise innovation. Performance. Second, private enterprises should strive to improve their openness to obtain external creative and complementary resources to help enterprises shorten the research and development cycle and save $R \& D$ investment costs, thereby accelerating the internalization of internal technology and improving the competitive advantage of enterprises. Third, the study found that the level of openness of private enterprises is relatively low. Therefore, the government should formulate relevant policies to protect the relevant rights and interests of private enterprises, and broaden the innovation channels of private enterprises in China to better encourage the openness of private enterprises in China. Innovate and enhance its innovation performance.

However, the research in this paper is not perfect. From the perspective of data selection, the data used in this paper is cross-sectional data, which does not reflect a continuous process and the number of private enterprise samples selected is relatively small. From the model point of view, this paper aims to explore the correlation between corporate openness and corporate innovation performance, but does not consider the possible intermediary or adjustment variables between the two, which will lead to a certain one-sided conclusion. Future research can select more microscopic samples in time and space, and can consider the institutional environment in which enterprises are located, as well as mediating intermediary variables such as absorptive capacity to more comprehensively explore enterprise openness and enterprise in the process of enterprise open innovation. The relationship between innovation performance, and the perspective of the heterogeneity of the enterprise, can further explore the mechanism of action between the two. For example, the heterogeneity of enterprise scale, the heterogeneity of the industry in which the enterprise is located, the heterogeneity of the enterprise from the perspective of the region, etc., all of which are conducive to further comprehensively examining the openness of the open innovation process of private enterprises in China. The micro-mechanism of performance.

\section{ACKNOWLEDGMENT}

First of all, I would like to thank the International Business School of Yunnan University of Finance and Economics for providing us with the opportunity and platform for this participation, as well as the help of the conference team staff in this conference.

Second, I would like to thank my teacher, Professor $\mathrm{Lu}$ Qicheng. From the determination of the topic selection, the formation of the research framework, the multiple revisions of the first draft, and the final completion of the thesis, Mr. Lu is dedicated to his efforts. Every step is condensed with his efforts and wisdom. Every circle and modification is full of him. Good intentions. His rigorous and pragmatic academic attitude, profound knowledge, keen academic insight, enthusiasm for work and the charisma of integrity and integrity have deeply infected me, and I am a model for lifelong learning. In the process of creating my thesis, Teacher Lu has always been full of hope for me, constantly urging me and inspiring me. When I am confused and confused, I can always get the teaching and enlightenment of Teacher Lu. His persistence and encouragement to me. It is the strongest spiritual support and dependence to overcome difficulties in my thesis writing process. The gratitude of the teacher, any language is difficult to achieve, only through the continuous efforts and progress of the future to meet the expectations of the teacher.

The authors thank other members of the research group for helpful, valuable, and constructive comments and suggestions on earlier versions of this paper. The paper is supported by the National Natural Science Foundation of China: "Influence of Internal and External Knowledge Management on the Open Innovation Ability of SMEs" (Project No.: 71872160, start and end time: 2019-2022); National Natural Science Foundation of China: "Knowledge Governance Affects Science and Technology Small and Medium-sized Theoretical and Empirical Research on Enterprise Dynamic Capability Improvement (Project No.: 71362014, starting and ending time: 2014-2017); National Natural Science Foundation of China: "Theoretical and Empirical Research on Inclusive Innovation Affecting China's Energy Poverty" (Project No. 71663057, Start and end time: 2017-2020); Yunnan Province Philosophy and Social Science Planning Project: "Study on Knowledge Dilemma and Governance Mechanism of Openended Innovation Capability of SMEs " (Project No.: YB2017083, start and end time: 2017-2019); Yunnan Province Key Projects of the Basic Research Program: "The Theory and Evidence of Knowledge Governance Affecting the 
Open Innovation Ability of Yunnan Sci-tech SMEs” (starting and ending time: 2019-2022).

\section{REFERENCES}

[1] Chinese entrepreneur survey system. Chinese enterprise innovation trend index: innovation environment, strategy and future -- 2017• Chinese entrepreneur growth and development survey report [J]. Management world, 2017(6):37-50

[2] Sun Linjie, Kang Rong, Wang Jingjing. Development and evolution of private enterprises' technical capabilities from the perspective of open innovation [J]. Science research, 2016, 34(2):253-259.

[3] Li Xianjun, Zhong Ling, Wang Jinglun, et al. Impact of open innovation and absorption capacity on innovation performance -- an empirical study based on Chinese automobile enterprises [J]. Scientific research management, 2018(1):45-52.

[4] Keupp, M., Gassmann.Determinants and.of open innovation [J]. R\&D Management.2009, 39(4):331-341.

[5] Leiponen A,Helfat C E Innovation objectives,knowledge sources and the benefit of breadth[J]. Strategic Management Journal.2010,31(2):224-236

[6] Guo Wei. An Empirical Study on the Impact of Innovation Openness on Enterprise Innovation Performance [J].Science Research Management, 2016, 37(10):43-50

[7] Guo Hai, Han Jiaping. The Impact of Open Innovation on the Growth of New Ventures in the Digital Context: The Mediating Role of Business Mode Innovation [J].Management Review, 2019, 31(06):186-198.

[8] Sapienza, Parhankangas A, Autio E. Knowledge relatedness and posts pin off Growth [J].Journal of Business Venturing. 2004, 19(6):809-829.
[9] Knudsen L. G. Determinants of Openness in R\&D Collaboration the roles of absorptive Capacity and appropriability [G] .Working paper for DRUIDDIME Academy winter, 2006.

[10] Huang F., Rice J. The role of Absorptive Capacity in Facilitating "Open Innovation" Outcomes: A study of Australian SMEs in the manufacturing sector [J]. International Journal of Innovation Management. 2009, 13(02):201220.

[11] Wang, F., Chen, J., Wang, Y., Lutao, N. \& Vanhaver-beke, W., 2014, "The Effect of R\&D Novelty and Openness Decision on Firms' Catch-Up Performance: Empirical Evidence from China", Technovation, Vol.34, pp. 21 30.

[12] Laursen K, Salter A. Open for innovation: The role of openness in explaining innovation performance among UK manufacturing firms [J]. Strategic Management Journal.2006, 27(2):131-150.

[13]Chen Yufen, Chen Jin. Open Innovation: Mechanism and Model [M]. Beijing: Science Press, 2008.

[14]Wei Jie, Zhang Zhuo. Innovation Openness and Enterprise Performance: Based on the Perspective of Export-oriented Open Innovation [J].Science and Technology Management Research, 2018, 38(09):9-16.

[15] Lichtenthaler U., Ernst H. Technology licensing strategies: The interaction of process and content characteristics [J].Strategic Organization, 2009.7(2):183-221

[16] Luan Qiang, Luo Shougui. R \& D subsidies, innovation and technological progress: An empirical study of state-owned enterprises and private enterprises based on comparison [J]. Studies in Science of Science, 2017, 35(4):148-155.

[17] Cui Weijun, Wang Wenjing, Fu Yu, Han Shuo, Zhao Jialu. Open innovation and innovation performance of Chinese manufacturing enterprises: an empirical analysis based on World Bank enterprise survey data [J]. Science and technology management research, 2017, 37(11):1-7. 